\section{Use of Objectives in Research Articles}

According to The Merriam-Webster Dictionary, the word "objective," when used as a noun, typically refers to a goal or a purpose. By definition, an objective should be goal-oriented. However, in research publications, the listed objective often describes the process of research rather than the purpose of the research. For example, a verb used in an objective statement might be "explore." A more appropriate verb might be "determine." The exploration (process-oriented) of data has a goal of determining differences in the population assessed.

We have noticed (and sometimes participated in) a trend toward this practice in the medical literature. Therefore, we decided to examine the research articles published in JMCP from 2015 through 2017 in an attempt to characterize the verbs used in their objective statements.

We reviewed the abstracts for every research article in this 3 -year period and recorded the verbs used for the objective statements. Two reviewers characterized the verbs as goaloriented or process-oriented.

Some verbs were inherently difficult to characterize according to these 2 categories. For example, the verbs "assess" and "evaluate" would be goal-oriented if they were used to denote the assignment of a value. In this case, the research methodology would have a scoring mechanism. However, in the research reports we reviewed, these verbs seemed to be used as a synonym for "review," which would be process-oriented.

The verb "compare" was even more troublesome. It was difficult to determine whether "compare" was used to describe the act of performing a parallel review (process-oriented) or the reporting of a parallel review (goal-oriented). Because of this difficulty, we designated "compare" as indeterminate.

When assessing the research articles, we assigned a numerical value to the verbs used. A goal-oriented verb was valued at 1 , while a process-oriented verb was assigned -1 . Verbs deemed indeterminate were valued at zero. When more than 1 objective verb was used, the scores for each verb were added together. A score of greater than zero was necessary to classify an article's verb use as goal-oriented.

We looked for the number of abstracts with goal-oriented objectives as a proportion of the total number of abstracts from the research articles. Of the 315 abstracts, goal-oriented verb usage was seen in 114 abstracts (36.2\%; Wilson interval $30.9 \%-41.8 \%)$.

We also performed a calculation after excluding 36 abstracts that had only indeterminate verbs. This calculation showed 114 of 279 abstracts (40.9\%; Wilson interval 35.1\%-46.9\%) with goal-oriented verb usage.

In addition to reporting on article results, we assessed the number of individual verbs used. The most common goal-oriented verbs used were "determine" (used 48 times), "estimate" (36), and "describe" (33), while the most common process-oriented verbs used were "evaluate" (77), "examine" (60), and "assess" (52).

In this sample, we found process-oriented objective verb use more common than goal-oriented use. We would like to challenge authors, editors, and reviewers to pay closer attention to this important aspect of a research paper.

Richard L. Ogletree, Jr., PharmD

Madison, MS

bogletree3@gmail.com

\section{Kayla Peeler Douglas, PharmD}

Mississippi Center for Advanced Medicine

Madison, MS

Lillie Floyd, PharmD

Bon Secours Memorial Regional Medical Center

Richmond, VA

\section{Meagan Cole Weber, PharmD}

Jewish Hospital

Louisville, KY

\section{Jennifer Reid Rawson, PharmD}

Mississippi Baptist Medical Center

Jackson, MS

Mallory Pullman, BS, PharmD Candidate

University of Mississippi School of Pharmacy

Oxford, MS

\section{DISCLOSURES}

No funding supported this project. The authors have no conflicts of interest to declare. 